\title{
Socio-cultural norms in ecological psychology: The education of intention
}

\section{Miguel Segundo-Ortin ${ }^{1}$}

Accepted: 11 February 2022

(c) The Author(s) 2022

\begin{abstract}
Although it is a common claim in the ecological psychology literature that our perception of the environment's affordances is influenced by socio-cultural norms, an explanation of how this is possible remains to be offered. In this paper, I outline an account of this phenomenon by focusing on the ecological theory of perceptual learning. Two main theses are defended. First, I argue that to account for how sociocultural norms can influence perception, we must pay attention not only to the education of attention but to the education of intention too. Consequently, I offer some ideas about how intention can be socio-normatively educated. Secondly, I hold that the education of intention occurs via the acquisition of habit-based preferences for particular actions. I claim that once we understand how these habit-based preferences relate to socio-cultural norms, the hypothesis that norms must be represented in the individual's mind for them to influence affordance perception is no longer needed. If this hypothesis is on the right track, we can have an explanation for how perception can be normatively shaped and direct (non-mediated by internal representations and inferences) at the same time.
\end{abstract}

Keywords Ecological psychology · Affordances - Socio-cultural norms · Habits · Education of intention · Perceptual learning

\section{Introduction}

A crucial aim of ecological psychology is to explain how organisms can purposefully control their action on the basis of what they perceive. In building such an

Miguel Segundo-Ortin

miguel.segundo.ortin@gmail.com

1 Department of Philosophy and Religious Studies, Faculty of Humanities, Utrecht

University, Utrecht, The Netherlands 
explanation, ecological psychologists are famous for introducing two radical hypotheses (Gibson, 1966, 1979[2015]; Turvey 2019; Segundo-Ortin et al., 2019; Warren, 2021). First, that our perception is primarily of affordances - viz., the opportunities for action an environmental setting offers to a particular observer. Second, that we perceive the affordances directly, this is without mediating inferences and mental representations. This is possible because affordances are specified by the information contained in the ambient energy array.

In the last years, ecological psychology has become a leading framework in the socalled "radical embodied cognitive sciences" (Chemero, 2009). Nonetheless, there are also critical voices in the field that claim that the theory, as articulated thus far, cannot account for a crucial aspect of human perception and action: namely, the fact that our perception of affordances is shaped by the socio-cultural norms that rule within the communities we partake in (Costall, 1995, 2012; Heft, 2007, 2018; HerasEscribano, 2019; Segundo-Ortin, 2020; van Dijk \& Kiverstein, 2020). In short, the problem arises from the following observation. Since socio-cultural norms are not specified in the perceptual information, then it is not clear how they can play a role in how individuals perceive and act upon the affordances of the environment. To solve this issue, a series of researchers have proposed that the norms are represented within the individual's mind (Bispinck-Funke, 2017; Borghi, 2018; Rochat, 2015; Thill et al., 2013). Once they are represented, so the reasoning goes, they are used to infer what the situation affords from a socio-normative perspective. However, this view contradicts the hypothesis of direct perception. Hence, the following questions arise: How do social norms influence perception if not in the form of mental representations? How can the existence of social norms be reconciled with the idea of direct perception defended by ecological psychologists? Insofar as ecological psychologists do not offer a satisfactory answer to these questions, the theory falls very short of being a genuine account of human perception and action.

The aim of this paper is to outline a positive but programmatic answer to these questions. The answer is programmatic in that it identifies ways in which we can expand current ecological psychology to explain how affordance perception and action can be permeated by social norms. To do so, I will focus on the ecological theory of perceptual learning. This paper will defend two main theses. First, I hold that in order to account for how socio-cultural norms can permeate perception, we must pay attention not only to the education of attention, as most ecological psychologists do, but to the education of intention. I claim that it is only after the individuals know what it is acceptable for them to do (education of intention) that they can educate their attention to detect the information that specifies the appropriate affordances. This education of intention, moreover, is a social phenomenon that requires the collaboration and correction of other members of the community. Hence, I propose the notion of "social education of intention" to make sense of this view. Secondly, I hold that the education of intention occurs via the acquisition of habit-based preferences (and accompanying attention habits) for particular actions. Such habits are acquired through social training and make us more prompted to perceive and act upon some affordances instead of others and in particular contexts. Once we understand how these habits relate to socio-cultural norms, and how we learn them, the hypothesis that norms are represented in the individuals' brains is no longer needed. 
A few clarifications are in place before continuing. First, I understand norms as criteria of correctness that allow us to evaluate or assess how we and others behave (Heras-Escribano \& de Pinedo-García, 2018). It is against these normative standards that we can say of particular actions that they are correct or incorrect, right or wrong, etc. Second, I understand socio-cultural norms as those that have their origin in the sustained practices, customs, and conventions within a community of agents. ${ }^{1}$ Third, I distinguish norm-following behavior from the explicit articulation of norms (see Bispinck-Funke 2017; Buskell, 2015; Rietveld, 2008). This distinction aims to capture the well-known fact that we can behave appropriately without having to think explicitly about the norms that apply to our actions. This, of course, does not exclude the fact that norms may be sub-consciously represented; hence the challenge of explaining norm-following perception and action in a non-representational way.

The structure of the paper is as follows. In Sect. 2, I elaborate on the difficult fit that social norms have in ecological psychology. There, I present the challenge of explaining how socio-cultural norms can permeate perception without being represented. Section 3 begins articulating the positive proposal of this essay. First, I present an argument for the importance of understanding the education of intention in developing an ecological theory of normative perception and action. Second, I draw from Rogoff et al.'s work in guided participation (Rogoff et al., 2011; Rogoff, 2003 ) to explain how intentions are socially educated. Finally, in Sect. 4, I elaborate on the Deweyan notion of habit in order to answer the challenge of offering a non-representational explanation for how socio-cultural norms shape perception. By elaborating on the social education of intention and on the Deweyan theory of habits, this paper aims to contribute to the work already initiated by well-known ecological psychologists such as Costall (1995), Reed (1996), or Heft (1989, 2001, 2007, 2017), among others.

\section{The difficult fit of social norms in ecological psychology}

Although affordances are traditionally understood in terms of body-environment relations - e.g., the relationship between the length of my legs and the height of a step -, it hasn't gone unnoticed by ecological psychologists that human perception-action is often shaped by social norms. Take J. J. Gibson's distinction between "expedient" and "proper" behavior as an example. Expedient behavior, he claims, "is that which satisfies biological drives. Proper behavior is that which conforms to customs and mores" (1950, p. 155). When we are hungry at work, we do not simply take any sandwich we find on a table. Instead, we "go through highly roundabout and inexpedient acts such as purchase [food]" (p. 153). Similarly, kids must learn to ask politely for cookies instead of snatching them.

Following this and other related examples, a series of theorists have argued that our relationship with the affordances of the environment does not depend on the detection of information only. Rather, this relationship is also affected by the social

\footnotetext{
1 The socio-cultural norms reflect "the group's expectations for how anyone who would be one of "us" should act, on pain of admonishment, punishment, or ostracism” (Tomasello, 2019, p. 254).
} 
norms of the community in which partake (Costall, 1995, 2012; Heft, 2001, 2017, 2018; Pedersen \& Bang, 2016; Rietveld \& Kiverstein, 2014). As Heras-Escribano rightly notes, "our social norms and conventions share their space with our individual perception of affordances, and sometimes our norms exert some pressure for not taking certain affordances given some social conventions" (2019, p. 175). Besides, it is often the case that social norms do not affect all members of the group in a homogeneous way. By contrast, Reed argues that social norms involve specialized roles related to gender, age, or socioeconomic status, and these roles "produce constraints on what affordances can be utilized, by whom, and when" (1993, p. 52, emphasis original).

Moreover, it is also the case that some affordances can only be perceived in the context of particular norms. For example, although some insects afford nutrition for human beings, most people in Western cultures do not perceive insects as edible. The reason for this is that these people have not grown up in communities where eating insects is encouraged. The same can be said about J. J. Gibson's much-discussed example of mailboxes (1979[2015], p. 130). For a metal box in the street to afford the possibility of sending and receiving letters, there must be a community with an organized postal system. Costall $(1995,2012)$ coined the notion of "canonical affordance" to refer to the affordances that can only be perceived against the background of specific socio-cultural norms.

Despite the widely accepted view that social norms influence our perception and take of affordances, "there is the issue of how to reconcile this fact with a lawful, ecological approach to cognition" (Heras-Escribano, 2019, p. 176). The problem is that an ecological theory that focuses exclusively on analyzing the role that perceptual information has on perception cannot account for the fact that human perception is also shaped by the socio-cultural context in which we live. ${ }^{2}$ To use an example from Heft (2003, pp. 157-158), although it may be true that the invariant ratio of leg length to the step riser height specifies the possibility of climbing a surface (Warren, 1984), this abstract mathematical function does not help us explain why we usually don't experience our office's tables as climbable. ${ }^{3}$ The same holds for the case of insects we mentioned above. This means that we cannot fully explain our relationship with all the affordances of the environment by relying on the traditional explanatory resources offered by the theory exclusively. This reasoning is behind Heft's concern that "it remains to be seen whether [ecological psychology] as articulated thus far can adequately capture the socio-cultural dimensions of human action and experience" (2017, p. 124; see also Pedersen \& Bang 2016, p. 738).

When facing this problem, some philosophers and cognitive scientists claim that if there is no information in the ambient energy array that specifies which tables ought not be climbed, then this information must be internally represented. From this,

\footnotetext{
${ }^{2}$ Heras-Escribano writes: "agents sometimes relate the taking of affordances to what is it the right thing to do in different circumstances. In this way, the social environment enters the picture as a key factor for regulating the taking of affordances, a factor that is as important as the nonsocial environment" (2019, p. 109). Later, he insists that "we should emphasize agency and normativity in order to clarify what allows us to perceive and take affordances" (pp. 113-114).

${ }^{3}$ As Heft puts it, even though the table affords climbing "[f]rom the standpoint of motor action", it does not do so "from the standpoint of action in social context" (2003, p. 158).
} 
they conclude that cases of affordance perception involving socio-cultural norms are "driven by higher-order semantic abitilies" (Zipoli Caiani, 2021, p. 4196), and require making inferences based on pre-stored mental representations of the relevant norms (see Borghi 2018; Colombo, 2014; Thill et al., 2013). ${ }^{4}$ This hypothesis, however, is potentially fatal for ecological psychology. The reason is as follows: If they are right that such cases need to be explained by appealing mental inferences and representations, then it follows that ecological psychology is inadequate to explain much (if not all) of human perception (Zipoli Caiani, 2021, pp. 4197-4198), as cases of affordance perception involving socio-cultural norms are pervasive for human beings.

I hold that in order to overcome this objection, we need a theory that explains how we learn and incorporate socio-cultural norms so that they can influence perception without assuming that these norms are implemented in the form of internal representations that mediate and transform perception. Put differently, we need an account for how our perception can become normatively shaped that does not render perception of affordances indirect. Providing this account is the aim of this paper.

\section{Social perceptual learning and the normative education of intention}

Ecological psychologists put a great emphasis on the importance of perceptual learning, or rather, perceptual-motor learning (Gibson \& Pick, 2000; Adolph et al., 2019). According to them, animals must learn to perceive the relevant affordances to engage the environment successfully. My claim in this section is that for understanding how socio-cultural norms can shape the individuals' perception, we must reconsider how we understand perceptual learning. More specifically, I argue that in order to comprehend the role that social norms play in the individuals' perception and action we must begin by understanding the importance of the "education of intention" (Jacobs $\&$ Michaels, 2007) in the process of learning to perceive affordances. After this, I will offer ideas about how intention is socially educated, thus countering the traditional individualist account adopted by most ecological psychologists.

\subsection{Perceptual learning and the education of intention}

In their now classical paper on perceptual learning, James and Eleanor Gibson (1955) argue against the idea that perceptual learning requires the "enrichment" of ambiguous sensory data with representations of memories. Instead, they conceive of it as a process of increasing "differentiation." According to them, perceptual learning consists of detecting new, not previously registered information, as well as in refining our capacity to discriminate the useful from the useless information for the task at hand (see also E. J. Gibson 1969; E. J. Gibson \& Pick, 2000).

\footnotetext{
${ }^{4}$ According to Bispink-Funke, "[r]ule-guidance and norm-guidance are phenomena that are grounded in mental processes with are accompanied by representations. Everyone whose conduct is guided by a rule has a mental representation of that rule [...]. The same is true for norm guided action" (2017, p. 112). For him, these mental representations of norms take the form of a conditional: "If the agents of a kind A are in situations of the type S, then they ought to do X" (p. 114).
} 
Traditionally, ecological psychologists interested in the question of perceptual learning have mostly focused on studying what they call "education of attention" (E. J. Gibson \& Rader 1979). In this framework, attention is understood as the controlled detection of the specific information for affordances, and the education of attention refers to the process by which agents come to detect those perceptual variables that are useful for attaining a particular task or goal.

This exclusive focus is also found in contemporary researchers. Take for instance the Skilled Intentionality Framework, of SIF (Rietveld \& Kiverstein, 2014; van Dijk $\&$ Rietveld, 2017). SIF offers a promising way to 'scale up' ecological psychology to explain instances of socio-culturally shaped cognitive skills, and then it is particularly interesting for the current discussion.

One key innovation of SIF is the idea that affordances are not relations between properties of the environment and the bodily skills of individuals only. Instead, affordances are understood in relation to "forms of life" - viz., the relatively stable set of practices and abilities shared by the members of a community. Forms of life manifest, for instance, in the expert performance of academics, architects, and so on, but also in the regular ways of interacting with everyday objects such as books or forks, and in the standard ways of behaving in social contexts - namely, when we offer our seat to the elderly in the bus, when we dress "appropriately" to go to the office, and so on. ${ }^{5}$

Rietveld \& Kiverstein (2014) refer to the myriad of affordances that belong to a form of life as the "landscape of affordances." Accordingly, being trained into a specific form of life involves, first, learning how to perceive and take advantage of a particular landscape of affordances. But mastering a specific form of life also requires acquiring the capacity to distinguish relevant from irrelevant affordances. For skilled individuals, the relevant affordances make it from the "landscape" to the "field," which means that they are experienced as more salient or relevant. The notion of "skilled intentionality" runs in parallel with another crucial notion: that of "situated normativity" (Rietveld, 2008; van den Herik \& Rietveld, 2021). Situated normativity refers to our capacity to reliably participate in social norms, acting in ways that are appropriate, but without having to deliberate about the norms themselves. Skilled intentionality makes situated normativity possible. ${ }^{6}$

Defenders of SIF stress the role that the education of attention has for the acquisition of skilled intentionality and situated normativity. For instance, Rietveld and Kiverstein argue that "in the process of education of attention the novice is brought to a selected aspect of the world that is of significance to the given practice and shown

\footnotetext{
5 According to SIF, the affordances that are available for an individual relate as much to the material environment as to the particular conventions and customs she is immersed in. Considering affordances as properties of the "socio-material" environment, they argue, allows us "to make sense of a chair not just as a place to sit but, as well, as a chair as it figures in its many ways in our human practices, inviting sitting, but also naming, pointing to or marveling at in a museum" (van Dijk \& Rietveld, 2017, p. 5).

6 The hypotheses of skilled intentionality and situated normativity are often combined with others, such as the postulation of "general ecological information" (Bruineberg et al., 2018; see also Withagen \& Chemero 2009). This sort of perceptual information is defined as "any regularity in the ecological niche between aspects of the environment, $x$ and $y$, such that the occurrence of aspect $x$ makes the occurrence of aspect $y$ likely" (Bruineberg et al., 2018, p. 5237). General ecological information, so the proponents suggest, makes it possible that non-specifying relationships, such as those involving socio-normative constraints, are directly perceived as affording actions.
} 
landmarks that orient his or her activities" (2014, p. 331). Accordingly, acting in a form of life allows the individuals to educate their attention so that they perceive the appropriate affordances.

For what matters, I take this idea to be largely correct. However, I would like to point out a complementary process: the education of intention (see Jacobs \& Michaels, 2002, 2007; Reed, 1993). The importance of intention for ecological psychology becomes evident if we notice that Gibsonians conceive of perception as an active process (see Brancazio \& Segundo-Ortin 2020). Unlike traditional approaches which assume that perception occurs when the perceiver's sensory organs are stimulated, ecological psychologists hold that in most cases perception involves active exploration, whereby this exploration is aimed to perceive particular affordances. J. J. Gibson makes this point clear:

What about the "intentionality" of perception when an observer is seeking information instead of simply having it presented to him? [...] What to me sounds promising is to begin with the assumption that active perception is controlled by a search for the affordances of the environment and that active behavior is controlled by perceiving these affordances (J. J. Gibson, 1974[1982], pp. 387-388).

Thus, although a single object (e.g., a chair) may afford different actions at the same time, we constrain our attention to detect the information that is relevant to what we intend to achieve - e.g., it is not the same information that is relevant for me if I want to jump over the chair or if I want to sit on it. This way, what we intend to achieve determines the affordances of the object that we perceive at a particular moment. The exact same point is emphasized by Heft when he claims that "an affordance is perceived in relation to some intentional act, not only in relation to the body's physical dimensions" (1989, p. 13).

The intentional direction of perception is even more prominent in cases where the information required to perceive an affordance is not immediately present. Think, for instance, in experiments where participants are tasked to estimate the length of an object based on active touch (Turvey \& Carello, 2011). Completing this task requires that individuals manipulate the object (through rotation and wielding) to discover perceptual variables that are not given in the environment. And a similar phenomenon occurs when animals perform head movements to assess distance before attacking their prey. The visual information available in motion parallax is not immediately present in the environment but is generated by the animal's own intentional actions. Thus, intention does not only affect our perception by constraining our attention to select perceptual variables in the ambient array. Instead, it also makes it possible that we access information not previously present in it.

This reasoning has led Jacobs and Michaels to claim that an ecological theory of perceptual learning cannot restrict itself to the education of attention but must account for the "education of intention" too:

Many perceptions and actions are possible in any situation. In the case of an approaching object for instance, a perceiver or actor might perceive whether the object is useful or harmful, whether he or she could catch, hit, or avoid the object or perhaps also the speed or size of the object. [...] Certain perceptions and actions are more beneficial than others and, with experience, humans and other animals might improve in choosing which of the possible perceptions and actions they intend to 
actualize. We have previously referred to this process as the education of intention. (2007, p. 326)

Following Jacobs and Michaels, I hold that whereas the education of attention refers to the individual's training to detect the most useful variable for the sought affordance, intention is educated when the individual learns what affordances are appropriate to seek and actualize given the situation. Moreover, I argue that the education of intention is complementary to the education of attention. This is so because “"'good" attention is perceiving what has utility for what the perceiver is doing or intends to do" (E. J. Gibson \& Rader 1979, p. 5). Thus, to educate our attention we must be committed to performing a particular action, and it is only in the context of this intentional action that we can evaluate whether our attention (i.e., our capacity to control the information we detect and the affordances we perceive) is improving.

Although the education of intention has received comparatively less attention in the ecological literature about perceptual learning, ${ }^{7} \mathrm{I}$ hold that understanding how intention is educated helps us illuminate the emergence of socio-normative perception and the development of situated normativity. While we learn "in which places in the environment to find the affordances relevant to our concerns and what aspects of the environment to attend to" (Rietveld \& Kiverstein, 2014, p. 331), we must also learn what actions are permitted to us, and in which particular situations. If we take seriously Gibson's idea that perception involves the active seeking for affordances, perceptual learning requires that we learn what affordances we are allowed to take advantage of. The process of learning what affordances are appropriate for us to seek and use is what I call the education of intention.

It follows from this view that it is a mistake to try to find out the basis of our perception of affordances in the available perceptual information only. The table, understood as a singular object, is the same whether it is located in the office or my house, and the information that specifies climbability is equally present in all circumstances. What changes, I hold, is our tendency to seek this information in different situations, and this tendency is constrained by our previously educated intentions. Therefore, I do not perceive the office tables as climbable because I do not pay attention to the information that specifies this action, but the reason why I do not pay attention to this information is that, when I am at the office, I do not intend to climb on the tables. My intentions have been normatively shaped, and this is reflected in how I perceive the environment's affordances. The education of attention and the education of intention are thus complementary processes.

Crucially, the education of intention is manifested both at the reflective and prereflective levels. For instance, I can deliberate about what it is more appropriate to do if I have a deadline in two days and my friends are asking me out and reach the conclusion that I should stay at home to finish the paper. In this situation, I use selfdirected speech to control my attention, focusing on the specific aspects of the environment that are relevant to what I intend to do (Brancazio \& Segundo-Ortin, 2020). Two aspects of this case deserve further consideration. First, this deliberation process does not occur ex nihilo. On the contrary, it is the result of years of conditioning

\footnotetext{
${ }^{7}$ Only Jacobs and Michaels $(2002,2007)$ have mentioned the education of intention as a relevant phenomenon in perceptual learning. However, they do not elaborate on how this education occurs.
} 
to think that academic obligations should be prioritized. Second, the claim that our deliberation affects our perception of the environment's affordances does not imply that perception becomes indirect. My deliberation does not mediate what I perceive in the sense of transforming the information into something else. By contrast, deliberation here is used to explore the environment, as a way to make sure that I perceive the affordances that are relevant for my current purposes. Moreover, this intentional guidance of attention can occur unconsciously too. Recall the previous example of the office tables. I do not need to remind myself that I should not climb upon the tables every time we enter the office. Rather, because of my previous history, the option of climbing upon the tables is just out of consideration, and I do not enter the office trying to perceive whether the tables are climbable.

To further illustrate this point, I believe it is useful to think about gender. Here, I follow Brancazio (2019) in understanding gender as referring primarily to "an associated and loosely unified set of socio-cultural norms, roles, and expectations historically organized around presumptions related to a sex binary" (p. 432). Elaborating on Pacherie (2014), Brancazio argues that repeated exposition to gender archetypes influence our individual agency (and our individual perception of affordances) through the shaping of our conscious and unconscious intentions. Similarly, drawing from Haslanger (2012, 2016), Ayala (2016) claims that gender roles are to be understood as "nodes" in a social structure. These social structures include relations between people (being a parent of, an employee of, a subordinate to, and so on) and with things, and these relations are experienced in terms of affordances that individuals are allowed to take advantage of. Hence, "[a]cknowledging this uneven distribution of locations plays a crucial role in understanding and explaining why some individuals, but not others, regularly perceive and exploit certain affordances in certain context, and why this is not exclusively dependent on their intrinsic properties" (Ayala, 2016, p. 882). Examples of these "structural injustices" range from the tendency of men to dominate conversations and processes of decision-making by interrupting other interlocutors, and especially women (Karpowitz \& Mendelberg, 2014), to the uneven occupation of the physical space observed between boys and girls in schools, where boys tend to monopolize most of the playing ground, relegating girls to the margins (Thorne, 1993). Even though Ayala does not mention the education of intention explicitly, I think this idea fits well in her account. Following Brancazio (2019), I maintain that learning to be a woman or a man in a particular society (or social structure) involves, among other things, learning what actions are permissible and, with this, what affordances are appropriate to seek and use. I hold that the fact that women systematically use different (and even fewer) affordances than men in particular shared contexts can be partially explained by appealing to the normative education of intention.

\subsection{The social education of intention}

Despite the efforts of well-known theorists to account for the social and cultural influences on perception and action (see e.g., Heft 2001, 2007, 2017, 2018; Reed, 1993, 1996; Costall, 1995, 2012), I agree with Adolph \& Hoch (2019) that most experiments in ecological perceptual learning focus on the activities of individual agents, 
thus ignoring social interactions. ${ }^{8}$ However, since my interest is in socio-cultural norms, it would not make much sense to adopt an individualistic approach toward perceptual learning. Consequently, I propose to look for resources to explain this learning outside ecological psychology to account for the education of intention.

It comes as no surprise that children are in contact with social norms from birth. We know, for instance, that 2-month old babies react to the facial expressions of their caregivers, and that they use this information to regulate their actions (Reddy, 2015; Adolph \& Hoch, 2019). Crucially, by detecting the emotional responses that their actions produce in adults, children begin to acquire a basic knowledge of acceptable behaviors. ${ }^{9}$ Another way in which young children get in contact with social norms is by imitation. We know that human beings tend to imitate the behavior of others and that this imitation plays a crucial role in the development and learning of particular skills. Moreover, through imitation children also begin to incorporate specific perception-action patterns that are already fully subject to social norms (Hardecker \& Tomasello, 2017).

Providing a comprehensive list of all the processes that contribute to the learning and acquisition of normative behavior is beyond the scope of this paper (but see Segundo-Ortin \& Satne 2022). Instead, I want to elaborate on a particular process that I think is essential for the social education of intention. This is commonly referred to as "guided participation" (see, e.g., Rogoff 2003; Rogoff et al., 2011; Lave, 2019). ${ }^{10}$ As Rogoff explicates, the notion of guided participation was introduced to emphasize that much of our social learning occurs through the active participation of newcomers in taking new roles and social responsibilities. Consequently, learning by guided participation takes place in the context of concrete social activities which novices are encouraged to observe and engage with, and it is embedded in endeavors that have social significance for the community:

Guided participation focuses on the side-by-side or distal arrangements in which children participate in the values, skills, and practices of their communities without intentional instruction or even necessarily being together at the same time. It includes varying forms of participation in culturally guided activities through the use of particular tools and involvement with cultural institutions. (2003, p. 284)

Learning by guided participation is important for different reasons. First of all, while only some societies can afford to segregate children from the community life,

\footnotetext{
${ }^{8}$ A good example of this individualistic approach is the direct learning theory (Jacobs \& Michaels, 2007). Even though it is the most thorough and empirically supported ecological theory of perceptual learning to date, it only considers the "information for learning" that emerges from the individuals' continuous interactions with the task settings.

${ }^{9}$ The caregiver's reactions, Krueger suggest, “encode the norms, values, and patterned practices distinctive of their specific socio-cultural milieu. [...] These physical interventions are thus arguably the earliest examples of social practices that scaffold the infant's cognitive development and shape the development of their cultural education" (2013, p. 40).

${ }^{10}$ This notion sometimes appears as "intent community participation" (Rogoff et al., 2007), "learning by observing and pitching in" (Paradise \& Rogoff, 2009), or "legitimate peripheral participation" (Lave, 2019). This form of learning opposes to others that focus on explicit instruction and repetition exclusively. It is worth mentioning that the work of Barbara Rogoff is already mentioned by Heft (2001) as a potential ally for an ecological psychology that aims to explain how socio-cultural norms can influence perceptual learning. I thank a reviewer for the pointer.
} 
creating spaces (e.g., schools) where they can learn practical skills and manners outside their societies' productive activity, in most societies children are encouraged to take an active role in the economic life of their communities. For instance, in many societies, young children get acquainted with calculus and other mathematical skills when they help their families sell the product they have grown at the local market, thus contributing to their collective sustenance (Cole, 2003). It does not follow, however, that guided participation only occurs in societies where schooling is not common; instead, guided participation is ubiquitous. For instance, it occurs when girls are encouraged to help their mothers take care of younger siblings after school. In these situations, young girls are given active roles and responsibilities that are directly related both to what their family needs and what society expects from them. This implicit social training is essential for what I have been calling social education of intention:

Sharing the social and cultural fabric of everyday life provides children with implicit self-evident goals and purposes of learning, grasped as part of the activity being carried out in everyday family and community contexts. (Paradise \& Rogoff, 2009, p. 107)

Hence, the notion of guided participation emphasizes cultural learning as a socially situated and embodied process that occurs in the context of specific tasks and practices. This view resonates with the intuitions of some Gibsonian theorists such as Costall, for whom the idea "of an individual, a child, who is all by itself with the world of objects is a completely artificial abstraction. The individual is not simply thrown into the human world; it is introduced into this world by the people around it; they guide it in that world" (1995, p. 472). In the beginning, children are assigned tasks and are encouraged to observe how the role models behave. Later they are given full responsibility in carrying out such duties, sometimes under the supervision of others who will intervene if correction is needed. Through this guided participation, the expert members of the community create what Reed $(1993,1996)$ calls a "field of promoted action," which comprises the affordances "to which an individual attends because of consistent encouragement from others" (1993, p. 55). By being introduced to these fields of promoted actions, our intention to seek and use affordances gets shaped and trained.

Again, 'gender training' is a case in point (see Rogoff, 2003). Theorists of guided participation claim that gender differences are primarily nurtured by differences in the tasks and roles usually assigned to the individuals. In short, the idea is that we learn how to occupy a "node" on a gendered social structure (Ayala, 2016) by actively playing the roles associated with this node.

One interesting example is aggression. Multiple sociological and anthropological records show that physical aggression and adolescent antisocial behavior are more common among males than females across numerous societies. By contrast, teenage girls are reported to be more often engaged in nurturant behavior (see, e.g., Schlegel 1995). These observations can lead us to think that gender differences are somehow pre-wired and universal. This conclusion can be contested, nonetheless. For instance, Ember (1973) studied the impact that the assignment of infant care duties had for teenage boys in a Luo community in Kenya and discovered that Luo boys who were regularly assigned these tasks at home were less aggressive than the other boys within 
the same community. Importantly, taking care of the children is considered a "female work" within the Lou communities, and it is only assigned to boys in the absence of older sisters. For Rogoff, this and other studies suggest that "[d]ifferences between boys and girls in social relations, such as aggression and nurturance, reflect a clear relationship to the roles expected of men and women in many cultural communities" (2003, p. 192). This gender training has more significant effects too. For instance, different studies show that women are systematically underrepresented in STEM majors and careers, with the exception of those within the medical fields. One proposed explanation for this is the "role congruity theory." This theory suggests that STEM careers are not that appealing to women because they are not perceived as affording the consecution of values that are congruent with women-associated roles and expectations, such as helping and caregiving (Diekman \& Steinberg, 2013). Following this view, Yang and Barth conducted a large empirical study with major STEM students and concluded that "the socialization of gendered interests and the social roles that align with occupation goal affordances are key factors contributing to women's great interests in some STEM occupation more than others" (2015, p. 73).

Another crucial aspect of guided participation is that it emphasizes the learning process as something valuable for the community. This has two crucial consequences (Roggoff et al., 2011). First of all, novices need not be forced to comply with certain norms. By contrast, the motivation to behave appropriately comes from the fact that the appropriate actions are experienced as being useful. Second, the perceived value tends to create an unnoticed identification of the individual with the norm so that "strong dispositions [to behave appropriately] develop that may be beyond the grasp of consciousness" (Rogoff et al., 2011, p. 491). Both points echo the thoughts of Haslanger:

if females are expected to perform the role of mothering and to perform it well, then rather than coerce them to fulfill this role, it is much better for females to be motivated to perform it. So the norms must be internalized, that is, they must be understood as part of one's identity and defining what would count as one's success as an individual. (2015, p. 10).

In sum, I hold that guided participation in social roles and practices is responsible for a great deal of our social perceptual learning and, more specifically, our social education of intention. By actively participating in social roles, individuals educate their intention according to what is socially expected from them. This education of intention constrains what actions they deem appropriate and even desirable, and, with this, what affordances of the environment they seek to perceive and actualize.

\section{What do we learn when we learn social norms?}

So far, I have defended that one way our perception of affordances gets shaped by socio-cultural norms is through the social education of intention. While individuals learn how to search for the appropriate information (education of attention), they must also learn what affordances they are allowed to seek and take advantage of (education of intention). Hence, the education of intention is a key process to explain how the individual's perception of affordances can be normatively shaped. 
In this final section, I want to address a potential criticism to my proposal. This criticism may come from those who defend that social norms must be stored subpersonally as representations for them to play a role in the individuals' perception and action. According to this view, the education of intention requires that we internalize social norms in the forms of mental representations. Zipoli Caiani (2021) makes this point clear in the context of ownership. According to him, to explain why we respond differently to the same object depending on the object's owner, we must assume that affordance perception "is influenced by the classification of the visual target according to social norms concerning ownership" (p. 4196). For him, this implies that "although possible that some basic acts may be performed independently of topdown knowledge, the evidence shows that the detection of visual opportunities for action is driven by higher-order semantic abilities" (ibid., emphasis original). Importantly, the point is not that this process requires explicit deliberation about norms, but only that these norms must play a "filtering" role in perception by being represented internally (see Borghi 2018). Therefore, albeit this proposal is in principle compatible with the notion of situated normativity as articulated by Rietveld (2008), it contradicts direct perception.

From my point of view, to address this objection, we must be able to answer the following questions: Can we perceive affordances in a normatively appropriate way without having to represent the norms in our minds? What do we acquire when we learn to abide social norms, if not mental representations? How can the existence of social norms be reconciled with the idea of direct perception?

I propose to start facing these questions by looking at the notion of "habit." This notion has occupied a prominent position in the cognitive science literature in the last few years, often with an unclear meaning (Caruana \& Testa, 2020). As Barandiaran $\&$ Di Paolo (2014) show, although habits are often reduced to automatic and rigid responses to particular stimuli, there are richer and more elaborate conceptions of habits in the phenomenological and pragmatist traditions. Here, I propose starting my analysis by focusing on the notion as articulated by Dewey. Dewey puts a great emphasis on the importance of habits for structuring humans' life, ranging from how we walk to our reasoning techniques and systems of beliefs. ${ }^{11}$

To understand the Deweyan notion of habit, we must put it in the broader context of his criticism of the reflex arc (1898). According to Dewey, theories in psychology that buy into the general hypothesis of the reflex arc assume that organisms are passive beings that are affected by single stimuli that impinge on them, triggering first a psychological and latter a behavioral response - a "sensation-followed-by-ideafollowed-by-movement" (p. 358) - via the mechanistic activation of their nervous systems. For him, this assumption is wrong because it ignores that our experience of the world is active:

Upon analysis, we find that we begin not with a sensory stimulus, but with a sensori-motor coordination, the optical-ocular, and that in a certain sense it is the move-

\footnotetext{
11 The connection between ecological psychology and the pragmatism of John Dewey is not new (see, e.g., Heft 1989; Segundo-Ortin \& Heras-Escribano, 2021). For a detailed analysis of the intellectual roots of James Gibson's ecological psychology in pragmatism see Heft (2001).
} 
ment which is primary, and the sensation which is secondary, the movement of body, head and eye muscles determining the quality of what is experienced. (ibid.)

According to Dewey, because every experience is incorporated within the context of a goal-directed activity - namely, the act of looking, the act of reaching, the act of thinking - that structures what is found in the world, any theory of psychology must begin with the notion of act, not with the notion of stimulus.

Once we have understood the importance of acts in structuring experience, we can now appreciate the centrality that the notion of habit plays in Dewey's philosophy. It is not my aim to offer a complete account of this notion here, but rather to highlight four crucial aspects of it. Firstly, Dewey holds that habits are a source of intentional activity. As he tells us, habits are "demands for certain kinds of activity [...]. In any intelligible sense of the word will, they are will. They form our effective desires and furnish us with working capabilities" (Dewey, 1922[2007], p. 25). In accord with this view, I hold that one way in which the education of intention proceeds is by developing habit-based preferences for seeking and actualizing particular affordances.

But Dewey does not reduce the habit to a "predisposition to ways or modes of response" (p. 32) only. Rather, he believes that each habit has a perceptual component too: "Habit means special sensitiveness or accessibility to certain classes of stimuli, standing predilections and aversions [...] The medium of habit filters all the materials that reaches our perception" (ibid.). Thus, when we acquire a habit-based preference for certain action, we also learn to perceive the world in accordance with it: The perceptual information that is relevant for the actualization of this habit becomes more easily perceivable, in the sense that we are predisposed to pay attention to it. Habitbased preferences for particular actions are thus accompanied by attention habits toward certain specific information (see Segundo-Ortin \& Heras-Escribano 2021). As I see it, understanding the relationship between the emergence of habit-based preferences and attention habits is key to understanding how the education of intention and the education of attention relate.

Thirdly, Dewey puts a great emphasis on the social component of habits. For him, habits are often not just individual predispositions but have a social origin in customs, conventions, and norms. At this point, the notion of "perceptual practice" recently coined by Arango (2019) comes in handy. This notion aims to capture the idea that perception does not fully resolve itself in law-like perceptual information. On the contrary, our perceptual experience of the world often depends on the enactment of culturally informed habits of looking, listening, tasting, smelling, etc. For instance, experiments involving the measurement of eye movement have reported interesting differences in how US American and East Asian people look at the same scenes (Chua et al., 2005). While East Asian participants made more saccades to the background figures, Americans tended to fix their attention on the focal objects. These differences in "modes of looking" were later reflected in what participants reported. Whereas US Americans were more likely to recall the focal figures first, East Asian participants often began with the contextual background where the scene took place.

Finally, insofar as Dewey conceives of thought as a sort of action, he defends the existence of "intellectual habits" or "habits of thought" too. He is clear that the "formation of ideas as well as their execution depend upon habit" (p. 30), and that 
"thinking cannot itself escape the influence of habit, any more than anything else human" (1922[2007], p. 25). ${ }^{12}$

Having such a rich notion of habit at hand, we are now in conditions to face the questions with which we began this section. My answer is that individuals do not learn to behave normatively by internalizing norms in the form of mental representations. Instead, they do so by developing habit-based preferences and attention habits. These habit-based preferences can be reflective ("intellectual" in Dewey's terms) or un-reflective. For example, the habit-based preference of treating insects as a plague to be killed causes most adult Westerners to fail to perceive insects as something edible. This, however, is not the product of conscious deliberation: I don't need to remind myself that insects are not food, as I don't have to remind myself that I ought not to climb upon the office tables. Other habits are intellectual in the sense that they affect our deliberation process. This is the case of women who believe that particular STEM careers are not appropriate to them (Yang \& Barth, 2015), or my habit of thinking that academic duties should be prioritized over my social life.

Therefore, learning to be a woman, or a man, a mother, a father, a University Professor, a Ph.D. student, and so on, in a particular society requires, first and foremost, to acquire the right sort of habits to detect and take advantage of appropriate sets of affordances. These socially originated habits create differences in how individuals perceive the world, and these differences are directly related to what the community considers right or wrong from a normative point of view.

By no means does the previous reasoning attempt to negate the obvious fact that we sometimes make norms explicit. This happens, for instance, when we correct the behavior of others by saying things like "you're wrong, we behave in such-and-such way here." What I dispute, instead, is that these are acts through which we externalize a previously represented rule or norm. By contrast, a hypothesis that is consistent with my proposal is that we create the rules in situ as we reflect upon our habits, putting them in relation to those of the other members of the community, and enouncing them (Levine, 2015; van den Herik \& Rietveld, 2021). Moreover, it might be suggested, from a developmental perspective, that our capacity to behave normatively on the basis of habits precedes our capacity to make the norms explicit. As Rietveld rightly notes:

We should distinguish between explicit social norms and underlying patterns of activities. Explicit social norms are best understood as useful abstractions from a third-person perspective that articulate the regularities that are already manifest in the coordinated behaviour of a community of individuals. (2008, p. 988)

In sum, I hold that appealing to habit-based preferences (education of intention) and attention habits (education of attention) allow us to explain "why some individuals, but not others, regularly perceive and exploit certain affordances in certain contexts" (Ayala, 2016, p. 882) without compromising the hypothesis of direct perception. These habits condition what affordances of the environment we perceive and act upon, as well as form the basis of our expectations concerning how others should

\footnotetext{
${ }^{12}$ In fact, Dewey believes that once we take the notion of habit of thought seriously, we begin to realize that the mind-body dualism is unfounded, for it is based on a false dichotomy between theory and practice (pp. 73, 186).
} 
act and can be reflected upon and verbalized in the form of explicit rules. Surely, this latter capacity for reflecting upon habits needs to be investigated, but nothing requires that we assume the existence of representations in the mind of individuals to explain how agents come to perceive and behave appropriately in the first place. ${ }^{13}$

\section{Concluding remarks}

While some Gibsonians acknowledge that socio-cultural norms shape our individual direct perception of affordances, there is little work on how this shaping takes places. In this paper, I have tried to account for this by focusing on an often-neglected aspect of perceptual learning: the education of intention. First of all, I have argued that whereas individuals learn where in the environment they can find the specific information for affordances (education of attention), they must also learn what affordances are appropriate for them to use (education of intention). Thus, our educated intentions modulate how we perceive the environment because they modulate what affordances we seek to perceive. Secondly, I have proposed a new approach to the social education of intention based on the notion of "guided participation." According to this view, we educate our intention as we actively participate in social roles that are valuable for our community. Perceptual learning and the education of intention thus occur in the context of socially situated practices. Finally, I have proposed an answer to the challenge of explaining how social norms can influence direct perception by drawing upon Dewey's rich notion of habit. My proposal is that we do not learn to behave normatively by internalizing norms in the form of mental representations. Instead, we do so by developing habit-based preferences (both reflective and pre-reflective) and attention habits. Appealing to habit-based preferences and attention habits helps us explain how our individual perception can be normatively shaped and direct at the same time.

Acknowledgements I am grateful to Annemarie Kalis, Josephine Pascoe, Rebecca Zeilstra, and the audience of the Situated Perspectives on Agency and Normativity workshop at Utrecht University (The Netherlands) for their comments on earlier versions of this manuscript. This research was supported by the Nederlandse Organisatie voor Wetenschappelijk Onderzoek VIDI Research Project "Shaping our action space: A situated perspective on self-control" (VI.VIDI.195.116). Finally, I would like to acknowledge the influence and inspiration of Manuel Heras-Escribano and Nick Brancazio. This paper would not exist without our discussions.

Compliance with ethical standards The author declares that there is no conflict of interest in the subject matter or materials discussed in this manuscript.

\footnotetext{
${ }^{13}$ van den Herik \& Rietveld (2021) have argued that reflective normativity is continuous with unreflective normative actions. The key movement here is to adopt an "expressive view of language," according to which "verbal behavior is not the outward sign of private thought. Instead, thoughts are articulated in speaking" (p. 3). This verbal behavior is useful because it allows us to direct both our own attention and the attention of others to particular affordances, thus suggesting a way of treating the current situation (see also Brancazio \& Segundo-Ortin 2020). The same applies when we behave normatively by stating explicit norms (pp. 13-16). Making a norm explicit is a possibility afforded by the current appreciation of a sustained practice, as well as a way to negotiate the situation itself.
} 
Open Access This article is licensed under a Creative Commons Attribution 4.0 International License, which permits use, sharing, adaptation, distribution and reproduction in any medium or format, as long as you give appropriate credit to the original author(s) and the source, provide a link to the Creative Commons licence, and indicate if changes were made. The images or other third party material in this article are included in the article's Creative Commons licence, unless indicated otherwise in a credit line to the material. If material is not included in the article's Creative Commons licence and your intended use is not permitted by statutory regulation or exceeds the permitted use, you will need to obtain permission directly from the copyright holder. To view a copy of this licence, visit http:/creativecommons.org/ licenses/by/4.0/.

\section{Bibliography}

Adolph, K. E., \& Hoch, J. E. (2019). Motor development: Embodied, embedded, enculturated, and enabling. Annual Review of Psychology, 70(1), 141-164. https://doi.org/10.1146/ annurev-psych-010418-102836

Arango, A. (2019). From sensorimotor dependencies to perceptual practices: Making enactivism social. Adaptive Behavior, 27(1), 31-45. https://doi.org/10.1177/1059712318811897

Ayala, S. (2016). Speech affordances: A structural take on how much we can do with our words. European Journal of Philosophy, 24(4), 879-891. https://doi.org/10.1111/ejop.12186

Barandiaran, X. E., \& Di Paolo, E. A. (2014). A genealogical map of the concept of habit. Frontiers in Human Neuroscience, 8. https://doi.org/10.3389/fnhum.2014.00522

Bispinck-Funke, C. (2017). On the question of how social rules and social norms exist. Phenomenology and Mind, 13, 110-118. https://doi.org/10.13128/PHE_MI-22433

Borghi, A. M. (2018). Affordances, context and sociality. Synthese, 199, 12485-12515. https://oi. org/10.1007/s11229-018-02044-1

Brancazio, N. (2019). Gender and the senses of agency. Phenomenology and the Cognitive Sciences, 18(2), 425-440. https://doi.org/10.1007/s11097-018-9581-z

Brancazio, N., \& Segundo-Ortin, M. (2020). Distal engagement: Intentions in perception. Consciousness and Cognition, 79, 102897. https://doi.org/10.1016/j.concog.2020.102897

Buskell, A. (2015). How to be skilful: Opportunistic robustness and normative sensitivity. Synthese, 192(5), 1445-1466. https://doi.org/10.1007/s11229-014-0634-8

Caruana, F., \& Testa, I. (Eds.). (2020). Habits: Pragmatist Approaches from Cognitive Science, Neuroscience, and Social Theory. Cambridge: Cambridge University Press

Chemero, A. (2009). Radical embodied cognitive science. Cambridge, Mass.: MIT Press

Chua, H. F., Boland, J. E., \& Nisbett, R. E. (2005). From the cover: Cultural variation in eye movements during scene perception. Proceedings of the National Academy of Sciences, 102(35), 12629-12633. https://doi.org/10.1073/pnas.0506162102

Cole, M. (2003). Cultural psychology: A once and future discipline. Harvard: Harvard University Press

Colombo, M. (2014). Explaining social norm compliance. A plea for neural representations. Phenomenology and the Cognitive Sciences, 13(2), 217-238. https://doi.org/10.1007/s11097-013-9296-0

Costall, A. (2012). Canonical affordances in context.Avant: Trends in Interdisciplinary Studies, 3(2)

Costall, A. (1995). Socializing Affordances. Theory \& Psychology, 5(4), 467-481. https://doi. org/10.1177/0959354395054001

Dewey, J. (1922). [2007]). Human nature and conduct an introduction to social psychology. NY: Cosimo Books

Diekman, A. B., \& Steinberg, M. (2013). Navigating social roles in pursuit of important goals: A communal goal congruity account of STEM pursuits. Social and Personality Psychology Compass, 7(7), 487-501. https://doi.org/10.1111/spc3.12042

Ember, C. R. (1973). Feminine task assignment and the social behavior of boys. Ethos, 1(4), 424-439. https://doi.org/10.1525/eth.1973.1.4.02a00050

Gibson, E. J. (1969). Principles of perceptual learning and development. Prentice-Hall

Gibson, E. J., \& Pick, A. D. (2000). An ecological approach to perceptual learning and development. Oxford University Press

Gibson, E., \& Rader, N. (1979). Attention. In G. A. Hale, \& M. Lewis (Eds.), Attention and Cognitive Development (pp. 1-21). Springer US

Gibson, J. J. (1966). The senses considered as perceptual systems. Greenwood Press 
Gibson, J. J. (1974). [1982]). Notes on action. In E. Reed, \& R. Reed (Eds.), Reasons for realism. Selected essays of James J. Gibson (pp. 385-392). Hillsdale, NJ: Lawrence Erlbaum Associates

Gibson, J. J. (1979). [2015]). The ecological approach to visual perception. New York, NY: Psychology Press

Hardecker, S., \& Tomasello, M. (2017). From imitation to implementation: How two- and three-year-old children learn to enforce social norms. The British Journal of Developmental Psychology, 35(2), 237-248. https://doi.org/10.1111/bjdp.12159

Haslanger, S. (2012). Resisting reality: Social construction and social Critique. Oxford: Oxford University Press

Haslanger, S. (2016). What is a (social) structural explanation? Philosophical Studies, 173(1), 113-130. https://doi.org/10.1007/s11098-014-0434-5

Heft, H. (1989). Affordances and the body: An intentional analysis of Gibson's ecological approach to visual perception. Journal for the Theory of Social Behaviour, 19(1), 1-30. https://doi. org/10.1111/j.1468-5914.1989.tb00133.x

Heft, H. (2001). Ecological psychology in context: James Gibson, Roger Barker, and the legacy of William James's radical empiricism. New York, NY: Psychology Press

Heft, H. (2007). The social constitution of perceiver-environment reciprocity. Ecological Psychology, 19(2), 85-105. https://doi.org/10.1080/10407410701331934

Heft, H. (2017). Perceptual information of "an entirely different order": The "cultural environment" in The senses considered as perceptual systems. Ecological Psychology, 29(2), 122-145. https://doi.org/10 $.1080 / 10407413.2017 .1297187$

Heft, H. (2018). Places: Widening the scope of an ecological approach to perception-action with an emphasis on child development. Ecological Psychology, 30(1), 99-123. https://doi.org/10.1080/104 07413.2018.1410045

Heras-Escribano, M. (2019). The Philosophy of Affordances. New York, NY: Routledge

Jacobs, D. M., \& Michaels, C. F. (2007). Direct learning. Ecological Psychology, 19(4), 321-349. eih

Karpowitz, C. F., \& Mendelberg, T. (2014). The silent sex: Gender, deliberation, and institutions. Princeton University Press

Krueger, J. (2013). Ontogenesis of the socially extended mind. Cognitive Systems Research, 25-26, 40-46. https://doi.org/10.1016/j.cogsys.2013.03.001

Lave, J. (2019). Learning and everyday life: Access, participation and changing practice. Cambridge University Press

Levine, S. (2015). Norms and habits: Brandom on the sociality of action. European Journal of Philosophy, 23(2), 248-272. https://doi.org/10.1111/j.1468-0378.2012.00530.x

Pacherie, E. (2014). Conscious intentions. Open MIND. Frankfurt am Main: MIND Group

Paradise, R., \& Rogoff, B. (2009). Side by side: Learning by observing and pitching in. Ethos, 37(1), 102-138. https://doi.org/10.1111/j.1548-1352.2009.01033.x

Pedersen, S., \& Bang, J. (2016). Historicizing affordance theory: A rendezvous between ecological psychology and cultural-historical activity theory. Theory \& Psychology, 26(6), 731-750. https://doi. org/10.1177/0959354316669021

Reddy, V. (2015). Self in Culture: Early Development. In International Encyclopedia of the Social \& Behavioral Sciences (pp. 439-444). Elsevier. https://doi.org/10.1016/B978-0-08-097086-8.23010-9

Reed, E. (1996). Encountering the world: Toward an ecological psychology. Oxford University Press

Rietveld, E. (2008). Situated normativity: The normative aspect of embodied cognition in unreflective action. Mind, 117(468), 973-1001

Rietveld, E., \& Kiverstein, J. (2014). A Rich landscape of affordances. Ecological Psychology, 26(4), 325-352. https://doi.org/10.1080/10407413.2014.958035

Rochat, P. (2015). Self-conscious roots of human normativity. Phenomenology and the Cognitive Sciences, 14(4), 741-753. https://doi.org/10.1007/s11097-015-9427-x

Rogoff, B. (2003). The cultural nature of human development. Oxford University Press

Rogoff, B., Correa-Chávez, M., \& Silva, K. G. (2011). Cultural variation in children's attention and learning. Psychology and the real world: Essays illustrating fundamental contributions to society (pp. 154-163). Worth Publishers

Schlegel, A. (1995). A Cross-Cultural Approach to Adolescence. Ethos, 23(1), 15-32

Segundo-Ortin, M. (2020). Agency From a Radical Embodied Standpoint: An Ecological-Enactive Proposal. Frontiers in Psychology, 11. https://doi.org/10.3389/fpsyg.2020.01319 
Segundo-Ortin, M., \& Heras-Escribano, M. (2021). Neither mindful nor mindless, but minded: habits, ecological psychology, and skilled performance. Synthese, 199, 10109-10133. https://doi.org/10.1007/ s11229-021-03238-w

Segundo-Ortin, M., Heras-Escribano, M., \& Raja, V. (2019). Ecological psychology is radical enough: A reply to radical enactivists. Philosophical Psychology, 32(7), 1001-1023. https://doi.org/10.1080/0 9515089.2019.1668238

Segundo-Ortin, M., \& Satne, G. (2022). Sharing attention, sharing affordances: From dyadic interaction to collective information. In M. Wehrle, D. D’Angelo, \& E. Solomonova (Eds.), Access and Mediation: Transdisciplinary Perspectives on Attention (pp. 91-112). Berlin: De Gruyter Saur

Thill, S., Caligiore, D., Borghi, A. M., Ziemke, T., \& Baldassarre, G. (2013). Theories and computational models of affordance and mirror systems: An integrative review. Neuroscience \& Biobehavioral Reviews, 37(3), 491-521. https://doi.org/10.1016/j.neubiorev.2013.01.012

Thorne, B. (1993). Gender play: Girls and boys in school. Rutgers University Press

Tomasello, M. (2019). Becoming human: A theory of ontogeny. Harvard University Press

Turvey, M. T. (2019). Lectures on perception: An ecological perspective. New York, NY: Routledge

van den Herik, J. C., \& Rietveld, E. (2021). Reflective situated normativity. Philosophical Studies, 178, 3371-3389. https://doi.org/10.1007/s11098-021-01605-4

van Dijk, L., \& Kiverstein, J. (2020). Direct perception in context: Radical empiricist reflections on the medium. Synthese, 198, 8389-8411.https://doi.org/10.1007/s11229-020-02578-3

van Dijk, L., \& Rietveld, E. (2017). Foregrounding sociomaterial practice in our understanding of affordances: The skilled intentionality framework. Frontiers in Psychology, 7. https://doi.org/10.3389/ fpsyg.2016.01969

Warren, W. H. (1984). Perceiving affordances: Visual guidance of stair climbing. Journal of Experimental Psychology: Human Perception and Performance, 10(5), 683-703. https://doi. org/10.1037/0096-1523.10.5.683

Warren, W. H. (2021). Information is where you find it: Perception as an ecologically well-posed problem. I-Perception, 12(2), 20416695211000370. https://doi.org/10.1177/20416695211000366

Yang, Y., \& Barth, J. M. (2015). Gender differences in STEM undergraduates' vocational interests: People-thing orientation and goal affordances. Journal of Vocational Behavior, 91, 65-75. https://doi. org/10.1016/j.jvb.2015.09.007

Zipoli Caiani, S. (2021). Intensional biases in affordance perception: An explanatory issue for radical enactivism. Synthese, 198(17), 4183-4203. https://doi.org/10.1007/s11229-018-02049-w

Publisher's Note Springer Nature remains neutral with regard to jurisdictional claims in published maps and institutional affiliations. 